\title{
MATERI DIGITAL BERBASIS WEB MOBILE MENGGUNAKAN MODEL 4D
}

\author{
${ }^{1}$ Imam Solikin, ${ }^{2}$ Rahayu Amalia \\ ${ }^{1}$ Program Studi Manajemen Informatika, Fakultas Vokasi, Universitas Bina Darma \\ ${ }^{2}$ Program Studi Sistem Informasi, Fakultas Ilmu Komputer, Universitas Bina Darma \\ 1,2Jalan Jenderal Ahmad Yani No.03, Palembang, Sumatera Selatan, Indonesia \\ Email: imamsolikin@binadarma.ac.id, rahayu_amalia@binadarma.ac.id
}

(Diterima: 27 Februari 2019, direvisi: 9 Agustus 2019, disetujui: 10 Agustus 2019)

\begin{abstract}
ABSTRAK
Sekolah Menengah Kejuruan (SMK) RA Kartini merupakan sekolah yang di dalamnnya terdapat jurusan "Teknik Komputer dan Jaringan" disingkat dengan TKJ, yang beralamat di Sungai Sahang No. 5, Lorok Pakjo, Kecamatan Ilir Barat I, Kota Palembang Provinsi Sumatera Selatan. Model pembelajaran yang sekarang ini berjalan di SMK RA Kartini menggunakan Lembar Kerja Siswa (LKS), buku, materi fisik, menggunakan LKS, Buku, Papan Tulis, dan Proyektor yang terbatas dalam penggunaannya, hal seperti ini berakibat kesulitan dalam mengulang pelajaran karena harus belajar di tempat tertentu seperti sekolahan atau rumah. Salah satu cara untuk mengatasi problem tersebut dengan mengembangan model pembelajaran digital berbasis web mobile. "Model yang digunakan dalam pengembangan yaitu model 4D yang di dalamnya terdapat beberapa tahapan define, design, develop, and disseminate". Tujuan dari pengembangan dalam pembelajaran ini untuk mempermudah siswa dalam mempelajari ulang materi dan mempelajari materi yang tertinggal karena bisa diakses dimanapun secara online melalui dari smartphone.
\end{abstract}

Keywords: materi digital, web mobile, model 4D

\section{PENDAHULUAN}

Pada era digital ini, kemajuan teknologi smartphone dapat dimanfaatkan pada berbagai bidang salahsatunya bidang pendidikan. Kemajuan teknologi tersebut bisa dijadikan fasilitas untuk mendukung belajar mengajar seperti tambahan media belajar dalam bentuk materi berbentuk digital berbasis smarthpone. Aplikasi mobile merupakan aplikasi yang di-design khusus platform mobile (android, iOs, atau windows mobile) [1]. Web mobile atau mobile web berupa kumpulan halaman html berbasis web (browser) yang dapat diakses menggunakan perangkat smartphone atau tablet. Situs web mobile biasanya bersifat memberikan informasi dan sering memiliki design yang sederhana [2]

Materi digital berupa resume atau dokumen dalam format digital [3]. Modul berupa "bahan ajar yang disusun secara sistematis dengan bahasa yang mudah dipahami oleh siswa, sesuai usia dan tingkat pengetahuan mereka agar mereka dapat belajar secara mandiri dengan bimbingan minimal dari seorang pendidik" [4]. Penjelasan lain dari modul pembelajaran adalah "bahan ajar yang disusun secara sistematis dan menarik dimana didalam modul pembelajaran tersebut mencakup isi materi, metode, dan evalusi yang dapat digunakan atau dipelajari secara mandiri (belajar sendiri) untuk dapat mencapai competence yang diharapkan secara mandiri" [5]. Berdasarkan penjelasan diatas modul merupakan materi pembelajaran yang disusun secara sistematis agar mudah dipahami sehingga dapat dipelajari secara mandiri.

SMK RA Kartini merupakan sekolah menengah kejuruan yang di dalamnya terdapat jurusan TKJ, yang beralamat di Sungai Sahang, Kecamatan Ilir Barat I, Kota Palembang Provinsi Sumatera Selatan. Pada proses belajar mengajar di SMK RA Kartini sekarang ini menggunakan media pembelajaran yang dalam bentuk media LKS, buku, materi fisik, papan tulis, proyektor, dan buku tulis yang penggunaanya terbatas. Media pembelajaran yang ada sekarang hanya bisa dilakukan di tempat tertentu dalam proses belajarnya (dirumah atau disekolahan), dan waktu belajarnya tidak fleksible karena tidak sewaktu-waktu kita bisa belajaran, kerepotan apabila harus dibawa untuk dipelajari. Pemasalahan tersebut mengakibatkan siswa SMK RA kartini kurang maksimal dalam memahami materi mata pelajaran, sehingga berakibat pada pengetahuan siswa SMK RA kartini akan ilmu terbatas.

Dari permasalahan tersebut makan perlu adanya penambahan model pembelajaran seperti materi dalam bentuk digital yaitu berbasis web mobile, untuk media belajar tambahan. "Materi digital berbasis 
web mobile merupakan bahan ajar yang dapat diakses melalui smartphone secara online". Penelitian ini akan membangun model digital yang berupa materi digital berbasis web mobile. Tujuan dari pengembangan media ini untuk mempermudah guru dalam penyampaikan materi, mempermudah siswa mendapatkan materi, dan sebagai fasilitas tambahan model belajar siswa SMK RA Kartini Palembang yang bisa diakses dimana-mana melalui smartphone.

\section{TINJAUAN PUSTAKA}

Penelitian yang terkait yang dijadikan refrensi dalam penelitian ini "Implementasi $e$-modul pada Program Studi Manajemen Informatika Universitas Bina Barma berbasis web mobile” [3], yang menghasilkan aplikasi e-modul untuk Program Studi Manajemen Informatika, sedangkan penelitian yang dilakuakn lebih diterapkan pada Sekolah Menengah Kejuruan (SMK) yang digunakan untuk mendukung proses mengajar Guru dan meningkatkan belajar siswa. Adapun penelitian lain yang yang dijadikan refrensi "Penerapan aplikasi e-book school pada SMK Emhata OKI Sumsel berbasis web" [6], dan "Aplikasi Bahan Ajar Digital pada Sekolah MA. Miftahul Huda Tugu Agung Kab. OKI" [7], pada penelitian yang dikemukan oleh [6] dan [7] menghasilkan Buku Elektroknik dan Bahan Ajar Digital berbasis web, sedangkan pada penelitian yang dilakukan tujuan menghasilkan aplikasi yang dapat diakses online menggunakan smartphone dengan hasil tampilan aplikasi yang maksimal.

Adapun penelitian dengan judul "Aplikasi e-document pada Kantor Kepala Desa Tugu Jaya berbasis website" [8], dijadikan sebagai rujukankan karena penelitian ini juga mengahasilkan aplikasi yang digunakan untuk proses pendataan dokumen elektronik berbasis web. Pada penelitian [8] mempunya tujuan yang sama yaitu untuk mempermudah penguna dalam mengakses dokumen atau materi dalam bentuk elektronik atau digital. Proses pendigitalan juga dibahasan pada penelitian dengan judul "Perancangan papan informasi digital untuk kehadiran Dosen pada STIPER Sriwigama Palembang" [9]. Pada penelitian [9] mengahasilkan papan informasi digital, adapun perbedaannya pada penelitian [9] berbasis lokal sedangkan tujuan penelitian yang dilakukan berbasis web mobile.

\section{METODE PENELITIAN}

\subsection{Metode Research and development (R\&D)}

"Research and development $(R \& D)$ merupakan metode penelitian yang digunakan untuk menghasilkan produk tertentu dan menguji keefektifan produk tersebut" [10]. "Research and development $(R \& D)$ merupakan metode penelitian secara sengaja, sistematis, untuk menemukan, memperbaiki, mengembangkan, menghasilkan, maupun menguji keefektifan produk, model, maupun metode/strategi/cara yang lebih unggul, baru, efektif, efisien, produktif, dan bermakna" [11].

Berdasarkan definisi diatas maka dapat disimpulkan bahwa Research and development $(R \& D)$ merupakan metode penelitian yang digunakan untuk menghasilkan produk tertentu dan menguji keefektifan produk serta dilakukan secara sengaja dan sistematis.

\subsection{Teknik Pengumpulan Data}

"Teknik pengumpulan data adalah tahapan yang sangat strategis dalam penelitian, karena tujuan utama dari penelitian adalah untuk mendapatkan data dan menghasilkan informassi yang bermanfaat" [10].

1. Teknik wawancara, teknik ini dilakukan dengan pengumpulan data yang melalui komunikasi langsung antara penyelidik dengan subyek atau responden [12]. Wawancara dilakukan kepada guru SMK RA Kartini sebanyak 10 guru yang mengampu mata pelajaran dijurusan Teknik Komputer dan Jaringan. Wawancara dilakukan pada awal semester ganjil tahun 2018 (01 September 2018). Inti dari wawancara tersebut mengenai media pembelajaran apa saja yang sudah digunakan dan apa saja yang menjadi kendala dalam pembelajaran. Selain itu wawancara juga dilakukan terhadap siswa SMK RA Kartini, kelas X, kelas XI, dan kelas XII yang dari masing-masing diambil sepuluh (10) siswa untuk diwawancara. Inti wawancara terhadap siswa tersebut mengenenai kemudahan dan kesulitan dalam mempelajari materi.

2. Observasi, teknik ini dilakukan dengan pengamatan dan pencatatan secara sistematis terhadap unsur-unsur yang nampak dalam suatu gejala pada objek penelitian [13]. Peneliti langsung mengamati model pembelajaran dan media pembelajaran yang digunakan. Observasi dilakukan selama dua semester yaitu semester ganjil dan semester genap pada tahun ajaran 2017/2018. 
Dari hasil wawancara dan observasi maka perlu adanya penambahan model pembelajaran kearah digital supanya bisa diakses dan dipelajari dimana-mana.

3. Dokumentasi, teknik catatan kejadiaan yang sudah terjadi. Teknik ini bisa berbentuk tulisan, Gambar, atau karya-karya monumental dari seorang [11]. Dokumen yang dihasilkan dari pengumpulan data berupa materi-materi yang ada di SMK RA Kartini yang akan dirubah manjadi versi digital.

\subsection{Model Pengembangan}

"4D Model (define, design, develop, and disseminate) merupakan model pengembangan perangkat pembelajaran" [14]. Adapun tahapan dalam pengembangan model 4D, sebagai berikut:

1. Define, tahap ini untuk menetapkan dan mendefinisikan syarat-syarat pembelajaran antara materi matapelajaran, waktu belajar, lokasi belajar, .

2. Design, pada tahap ini dilakukan proses perancangan media pembelajaran yang diGambarkan menggunakan flowchart dan desain interface.

3. Develop, tahap ini menghasilkan produk pengembangan melalui dua tahapan, yaitu expert apprasial, and developmental testing.

4. Disseminate (penyebaran), ini merupakan tahap akhir dari pengembangan aplikasi yang digunakan dalam menyebarkan produk yang dikembangkan agar diterima pengguna (indivindu atau kelompok).

\section{HASIL DAN PEMBAHASAN}

\subsection{Define}

Define (pendefinisian), ini merupakan tahap dalam menetapkan dan mendefinisikan syarat-syarat pembelajaran, yang terdiri dari lima langkah, antara lain sebagai berikut:

1. Front and analysis pada tahap dilakukan diagnosis awal media pembelajaran yang digunakan pada SMK RA Kartini Palembang dalam meningkatkan efisiensi dan efektifitas pembelajaran,

2. Learner analysis ditahap ini peneliti mempelajari karakteristik siswa SMK RA Kartini Palembang seperti latar belakang pengetahuan, kemanpuan, motivasi dalam belajar dan lain-lainnya,

3. Task analysis tahap ini melakukan analisis semua tugas pokok yang harus dikuasai siswa SMK RA Kartini Palembang supanya bisa mencapai komtetensi minimal,

4. Concept analysis, melakukan analisis konsep yang akan diajarkan dan menyusun langkah-langkah secara rasional,

5. Specifying instructional objectives, memperlihatkan pembelajaran dan perubahan prilaku yang diharapkan. Mempermudah siswa dalam proses belajar dan meningkatkan minat belajar siswa terhadap materi-materi pembelajaran.

\subsection{Design (perancangan)}

Perancangan proses alur aplikasi materi digital digambarkan dengan flowchart [15], yang dijelaskan pada Gambar 1.

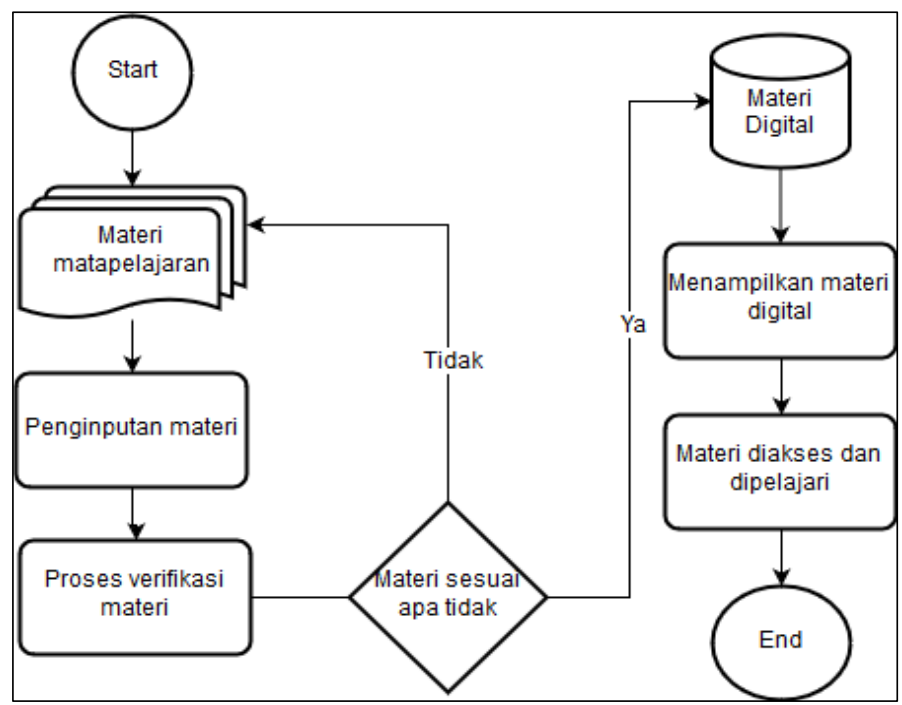

Gambar 1. Flowchart materi digital

Solikin, Materi Digital Berbasis Web Mobile Menggunakan Model 4D 
Perancangan tampilan awal aplikasi terdiri dari menu "materi digital" dan "login", yang bisa dilihat pada Gambar 2.

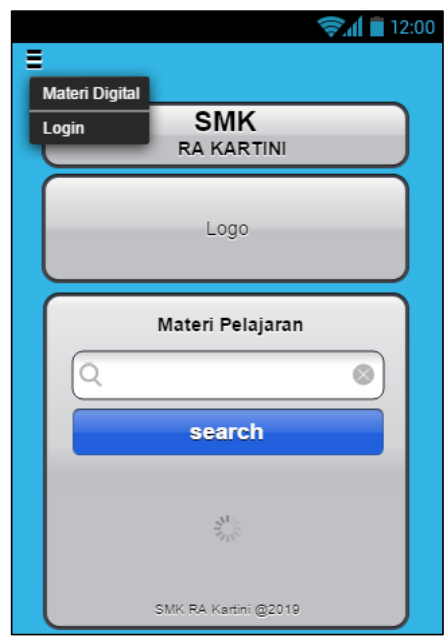

\section{Gambar 2. Desain tampilan materi digital untuk siswa}

Setelah perancangan awal dilanjutkan dengan membuat perancangan login yang difungsikan untuk masuk ke aplikasi pengelolahan data materi digital, perancangan dijelaskan pada Gambar 3.

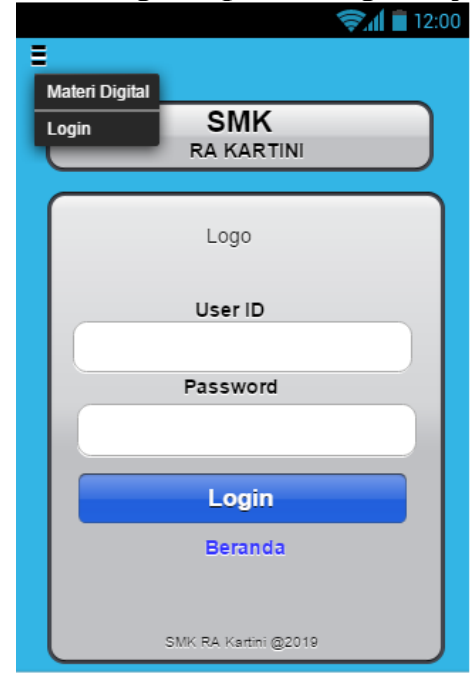

\section{Gambar 3. Login admin}

Selajutnya perancangan input materi yang digunakan untuk merubah materi fisik kemateri digital perancangan input materi digital dijelaskan pada Gambar 4.

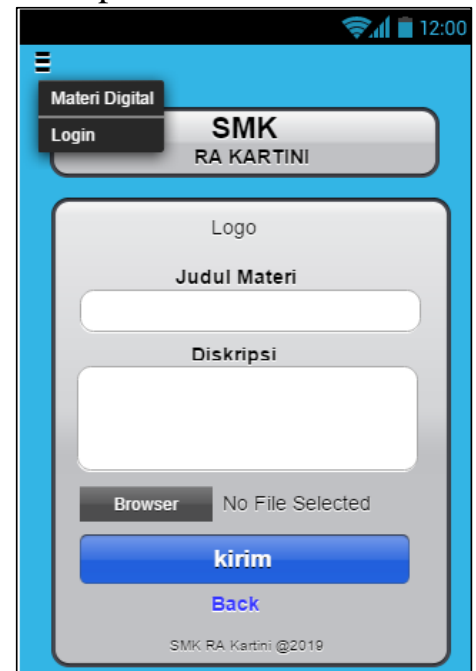

\section{Gambar 4. Desain input materi digital}


Pada perancangan tampilan akhir aplikasi meteri digital, berupa perangan untuk menampilkan hasil materi, perancangan data materi digital dijelaskan pada Gambar 5.

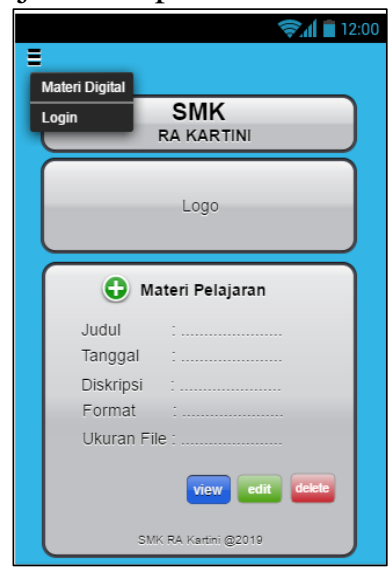

Gambar 5. Tampilan meteri digital pada admin

\subsection{Develop (pengembangan)}

1. Index materi digital

Interface index aplikasi materi digital muncul pada bagian pertama ketika aplikasi diakses, halaman ini dapat diakses secara umum tidak harus melakukan login terlebih dahulu, materi dapat dicari melalui fasilitas pencarian. Interface view materi digital jelaskan pada Gambar 6.

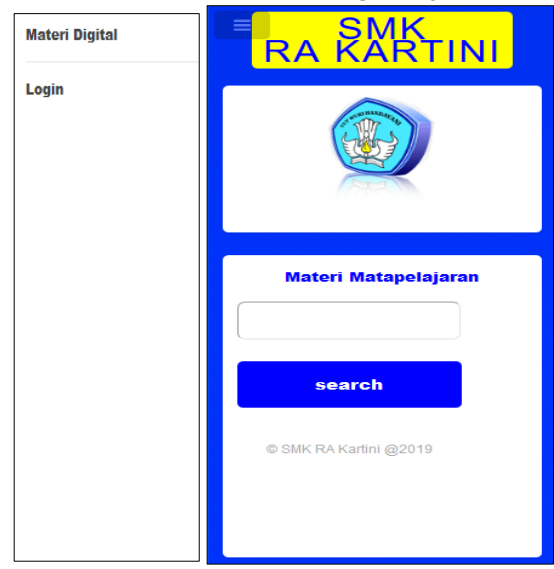

Gambar 6. View materi digital

2. Login

Halaman ini bisa diakses oleh admin yang mengelolah materi digital dengan userid dan password masing-masing. Admin ditugas melakukan pengecekan materi dan verifikasi apakah meteri terbut sesuai apa tidak, admin juga bisa melakukan penginputan materi. Interface login bisa dilihat pada Gambar 7.

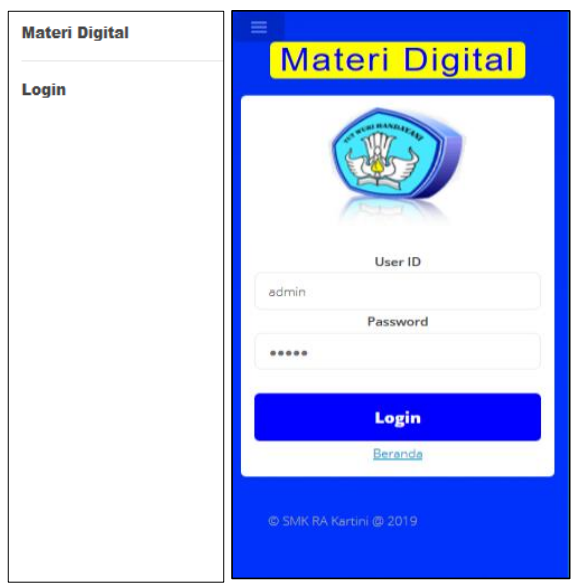

Gambar 7. Login 
3. View materi pada admin

Tampilan dikelolah oleh admin yang mempunyai fasilitas view materi digital untuk menampilkan isi materi, update untuk memperbaharui isi materi, dan delete untuk menghapus isi materi. Interface view materi digital pada admin, bisa dilihat pada Gambar 8.

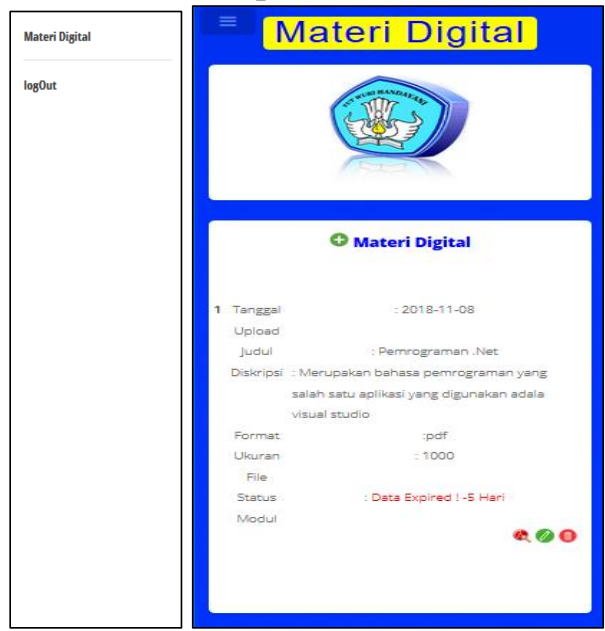

4. Add materi digital

\section{Gambar 8. View materi pada admin}

Add materi digital berfungsi untuk meng-input-kan materi baru yang nanti akan tampil diview pada admin dan view pada awal sistem. interface add materi bisa dilihat pada Gambar 9.

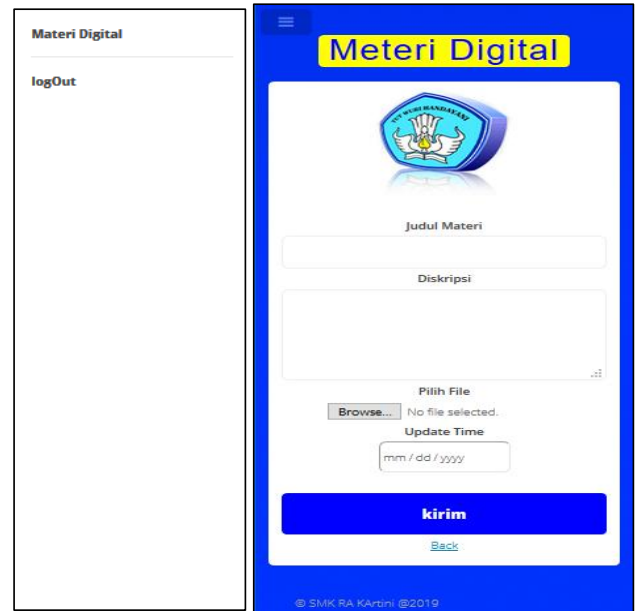

\section{Gambar 9. Input materi}

5. Hasil view materi

Tampilan ini merupakan isi dari materi yang dibuka dan muncul ketika tambol view diklik. Tampilan dapat diakses melalui tampilan awal sistem dan halaman admin. Dari tampilan ini pengguna dapat mempelajari isi materi pelajaran yang dinginkan pada SMK RA Kartini Palemban. Interface hasil view materi bisa dilihat pada Gambar 10.

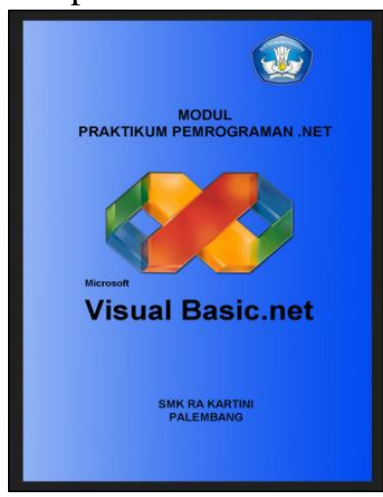

Gambar 10. Hasil view materi 
Pengujian interface aplikasi materi digital menggunakan black box dengan hasil sebagai berikut:

1. Interface materi digital siswa: materi digital nampil pada halaman awal aplikasi tanpa melakukan login, kesimpulan hasil pengujian diterima

2. Interface login admin: login hanya bisa digunakan oleh admin yang mempunyai hak akse, kesimpulan hasil pengujian diterima

3. Interface input materi digital: proses input materi digital dilakukan oleh admin yang sudah masuk kesistem melalui login, kesimpulan hasil pengujian diterima.

4. Interface meteri digital: merupakan meteri yang dalam bentuk tampilan file digital yang bisa di buka oleh admin dan siswa, kesimpulan hasil pengujian diterima

\subsection{Disseminate}

Pada tahap disseminate dilakukan pada siswa SMK RA Kartini dengan memberikan pelatihan kepada pengunaan aplikasi materi digital. Tujuan dari pelatihan penggunaan aplikasi meteri digital supaya siswa dapat mengetahui cara penggunaannya dan dapat merasakan manfaatnya, sehingga aplikasi tersebut dapat digunakan secara maksimal. Pelatihan tersebut dilakukan kepada siswa dengan dengan menjadi 3 sesi untuk sesi pertama kelas X dengan jumlah 25 siswa, sesi kedua kelas XI dengan jumlah 25 siswa, dan kelas XI dengan jumlah XII siswa. Hasil dari pelatihan aplikasi materi digital adalah siswa dapat dengan mudah menggunakan aplikasi karena dapat diakses melalui smartphone, materi dapat dibuka melalui smartphone, materi dapat dipelajari melalui smartphone, sehingga bias diakses dimanapun.

\section{KESIMPULAN}

Penelitian ini menghasilkan aplikasi yang berisi meteri digital, untuk mempermudah siswa dalam mendapatkan materi maupun mempelajari materi dimanapun, yang dapat diakses secara online melalui smartphone. Aplikasi yang dibangun mempunyai tujuan untuk meningkatkan belajar siswa. Dalam mengakses sistem ini perlu adanya jaringan internet, karena sistem ini dipublikasi secara online. Untuk hasil yang lebih meningkat dan bermanfaat lagi perlu adanya pengembangan kearah agak bisa diakses secara offline. Saran dalam penelitian ini agar bisa dilanjutkan dengan pengembangan ke arah online dan offline agar lebih mudah diakses dan dipelajari.

\section{REFERENSI}

[1] F. Y. Aulia and L. Yuldinawati, "Analisis Faktor Konfirmatori Motivasi Pada Pengguna Aplikasi Taksi Online Di Wilayah Bandung," eProceedings Manag., vol. 5, no. 1, 2018.

[2] M. Abdurahman, "Sistem Informasi Jadwal Perkuliahan Berbasis Web Mobile Pada Politeknik Sains Dan Teknologi Wiratama Maluku Utara," Indones. J. Netw. Secur., vol. 5, no. 2, pp. 4956, 2016.

[3] I. Solikin, "Implementasi E-Modul pada Program Studi Manajemen Informatika Universitas Bina Darma Berbasis Web Mobile," J. RESTI (Rekayasa Sist. dan Teknol. Informasi), vol. 2, no. 2, pp. 492-497, 2018.

[4] P. Andi, "Panduan Kreatif Membuat Bahan Ajar Inovatif Cetakan ke-4 (Yogyakarta." Diva Press, 2012.

[5] I. Anwar, "Pengembangan Bahan Ajar," Bahan Kuliah Online. Direktori UPI. Bandung, 2010.

[6] F. Purwaningtias and I. Solikin, "Penerapan Aplikasi e-book school pada SMK Emhata OKI Sumsel berbasis Web," J. Sist. Informasi, Teknol. Inf. dan Komput., vol. 8, no. 1, pp. 21-30, 2017.

[7] I. Solikin and D. Komalasari, "Aplikasi Bahan Ajar Digital pada Sekolah MA. Miftahul Huda Tugu Agung Kab. OKI," J. Media Inform. dan Komput., vol. 8, no. 1, pp. 63-69, 2017.

[8] I. Solikin and M. S. Putra, "APLIKASI E-DOCUMENT PADA KANTOR KEPALA DESA TUGU JAYA BERBASIS WEBSITE,” J. Cendikia, vol. 16, no. 1 Oktober, pp. 89-94, 2018.

[9] R. M. N. Halim, "Perancangan Papan Informasi Digital untuk Kehadiran Dosen pada STIPER Sriwigama Palembang," in Prosiding Seminar Nasional Darmajaya, 2018, vol. 1, no. 1, pp. 128-136. 
[10] M. P. K. Sugiyono, "Kualitatif, dan Kombinasi (Mixed Methods)," Bandung Alf., 2013.

[11] N. Putra, "Research \& Development penelitian dan pengembangan," Jakarta Raja Gravindo Persada, 2012.

[12] R. Yatim, "Metodologi Penelitian Pendidikan Kualitatif dan Kuantitatif." Surabaya: Unesa University Press, 2007.

[13] E. P. Widoyoko, “Teknik Teknik Penyusunan Instrumen Penelitian," Yogyakarta: Pustaka Pelajar, 2016.

[14] M. P. Trianto, "Model pembelajaran terpadu: Konsep, strategi, dan implementasinya dalam Kurikulum Tingkat Satuan Pendidikan (KTSP)," Kuala Lumpur: Kemetrian Pengajaran Malaysia, 2010.

[15] R. Afyenni, "Perancangan data flow diagram untuk Sistem informasi sekolah (studi kasus pada sma pembangunan Laboratorium unp)," J. Teknoif, vol. 2, no. 1, 2014. 